\title{
Platelet-derived growth factor and transforming growth factor beta synergistically potentiate inflammatory mediator synthesis by fibroblast-like synoviocytes
}

\author{
Sanna Rosengren, Maripat Corr and David L Boyle*
}

\begin{abstract}
Introduction: The objective of this study was to model the effects of transforming growth factor beta (TGF- $\beta$ ) and platelet-derived growth factor (PDGF), both present in rheumatoid arthritis (RA) synovia, on the behavior of fibroblastlike synoviocytes (FLS) in response to pro-inflammatory cytokine (interleukin (IL) $1 \beta$, tumor necrosis factor-alpha (TNFa)) challenge.

Methods: Gene and protein expression by fibroblast-like synoviocytes in vitro was studied by quantitative Polymerase Chain Reaction (qPCR), ELISA and multiplex bead cytokine assays. Intracellular signaling pathway activation was determined by Western blot for phospho-kinases and the use of specific inhibitors.

Results: In combination, TGF- $\beta$ and PDGF (2GF) synergistically augmented TNFa- or IL1 $\beta$-induced matrix metalloproteinase 3 (MMP3), IL6, IL8, and macrophage inflammatory protein 1 alpha (MIP1 a) secretion by FLS. Other FLS-derived mediators remained unaffected. Individually, neither growth factor significantly potentiated TNFa or IL1 $\beta$ induced MMP3 secretion, and only slightly enhanced IL6. The effect of 2GF on TNFa-induced gene expression was transcriptionally mediated; blocked by imatinib mesylate; and occurred even if 2GF was added as much as four hours prior to TNFa. In addition, a 15-minute pulse of 2GF four hours prior to TNFa stimulation yielded a synergistic response. The extracellular-signal-regulated kinase (ERK) and phosphoinositide 3-kinase (PI3K) signaling pathways were induced for at least four hours by $2 \mathrm{GF}$, as demonstrated by persistently upregulated levels of phospho-Akt and phospho-ERK. However, pharmacologic inhibitor studies demonstrated that the potentiating action of $2 \mathrm{GF}$ was dependent on PI3 kinase only, and not on ERK.
\end{abstract}

Conclusions: The combination of PDGF and TGF- $\beta$ dramatically potentiates FLS response to cytokines in a receptormediated and PI3 kinase-dependent fashion. These data suggest that 2GF contribute to synovitis by directing synovial fibroblasts toward a more aggressive phenotype in response to TNFa. Therefore, inhibition of growth factor signaling may constitute a complementary therapeutic approach to cytokine-targeted treatments for RA.

\section{Introduction}

Expression of the regulatory peptides, platelet-derived growth factor (PDGF) and transforming growth factor beta (TGF- $\beta$ ) are increased in synovial tissue and fluid of rheumatoid arthritis (RA) patients [1-4]. PDGF has been implicated in RA pathogenesis, mainly through its function as a growth factor for fibroblast-like synoviocytes

*Correspondence: dboyle@ucsd.edu

1 Division of Rheumatology, Allergy and Immunology, University of California at San Diego School of Medicine, 9500 Gilman Drive, La Jolla, CA 92093-0656, USA Full list of author information is available at the end of the article
(FLS) $[3,5]$. In contrast, the actions of TGF- $\beta$ are more complex. TGF- $\beta$ plays a crucial role in maintaining immunological tolerance through the inhibition of lymphocytes and macrophages [6]. On the other hand, it recruits and activates naive monocytes [6], stimulates proliferation [7] and induces aggrecanase synthesis [8] by FLS. Systemic administration of TGF- $\beta$ protects against development of collagen arthritis in mice [9], whereas direct injection of TGF- $\beta$ into rat joints leads to pronounced synovitis [10]. 
In addition to these growth factors, chronically inflamed RA synovia contain a multitude of inflammatory mediators that may act in concert with each other. In this context, aggravating as well as mitigating effects of growth factors and cytokines on FLS have been demonstrated. For example, PDGF was reported to enhance IL1 $\beta$-induced prostaglandin E2 production, while inhibiting collagenase synthesis [11]. Also, PDGF was shown to induce synthesis of IL8 and MIP1 $\alpha$, along with IL1 $\beta$, by FLS [12], and also to synergize with TNF $\alpha$ to stimulate IL1 $\beta$ secretion, although these results are somewhat confusing since FLS are not typically considered a significant source of IL1 $\beta$. On the other hand, TGF- $\beta$ was earlier shown to inhibit TNF $\alpha$-induced RANTES synthesis by FLS [13]. A systematic study of the nature of the interaction among these mediators was not undertaken to date. Hence, the interplay between PDGF, TGF- $\beta$, and cytokines such as TNF $\alpha$ and IL1 $\beta$ on the activation of FLS remains unclear, albeit of potential significance considering the abundance of these proteins in the RA synovial environment.

Consequently, we set out to systematically determine the effect of PDGF and TGF- $\beta$, alone and in combination, on inflammatory biomarker expression and secretion by FLS. We describe significant potentiation by PDGF and TGF- $\beta$ of the production of certain cytokines, chemokines, and matrix metalloproteinases (MMP) by FLS. This synergy was mediated by tyrosine-kinase receptor activation and dependent on PI3K, both of which are receiving attention as possible novel approaches to RA drug therapy.

\section{Materials and methods Reagents}

Cytokines and TGF- $\beta$ were obtained from R\&D Laboratories (Minneapolis, MN, USA). Imatinib mesylate (LC Laboratories, Woburn, MA, USA) was dissolved in water. All other reagents, including PDGF-BB, were from Sigma (St. Louis, MO, USA) unless otherwise noted. Stock solutions in DMSO (1000×) of PD98059 and LY294002 were kept at $-80^{\circ} \mathrm{C}$.

\section{Fibroblast-like synoviocytes (FLS)}

FLS were cultured from the synovial tissues of RA patients undergoing arthroplastic surgery, as previously described [14], after obtaining informed consent under approval from the University of California, San Diego Institutional Review Board, and maintained in Dulbecco's Modified Eagle Medium (DMEM) supplemented with antibiotics, glutamine, and $10 \%$ fetal bovine serum. Passages 4 through 8 were used in experiments. Cells were subjected to a two- to three-day reduced serum condition
( $0.1 \%$ fetal bovine serum) prior to stimulation to minimize baseline activity.

\section{Secreted protein assays}

FLS supernatants at 24 hours following stimulation were assayed by ELISA for IL6 (eBioscience, San Diego, CA, USA), MMP1, and MMP3 (GE Healthcare Life Sciences, Piscataway, NJ, USA). Standard curves were constructed by regression line fitting on $\log$ (absorbance) vs $\log$ (concentration). Levels of cytokines and chemokines in supernatants were determined by Luminex multiplex analysis (BioRad Bio-Plex assays, Hercules, CA, USA) from fourparameter standard curve fits.

\section{Gene expression assays}

Messenger RNA for IL6, MIP1 $\alpha$, and MMP3 were quantified by real-time TaqMan quantitative Polymerase Chain Reaction (qPCR), using FLS cDNA, with GAPDH used as a housekeeper (all reagents from Applied Biosystems, Foster City, CA, USA). Resulting threshold cycle (Ct) data were normalized to standard curves constructed from cDNA from IL1 $\beta$-stimulated FLS [15], yielding cell equivalents. The ratio between the specific cytokine and GAPDH cell equivalents (relative expression units, REU) is reported.

\section{Western blot}

FLS extracts were prepared in RIPA buffer with Complete Protease Inhibitors (Roche Applied Science, Indianapolis, IN, USA), denatured in sample buffer and $0.1 \mathrm{M}$ dithiotreitol, and fractioned on Invitrogen (Carlsbad, CA, USA) NuPage 4 to $12 \%$ precast gels. Following blotting to polyvinylidene fluoride (PVDF) membranes and blocking with $5 \%$ dry milk, blots were probed with antibodies against phospho- or total p38, JNK, Erk, or Akt, as well as with secondary anti-rabbit-IgG-HRP (all Cell Signaling Technologies, Danvers, MA, USA). GAPDH was used as a gel loading control (antibody from Santa Cruz Biotechnology, Santa Cruz, CA, USA). Membranes were developed with Immun-Star WesternC ECL substrate (BioRad, Hercules, CA, USA) and imaged on a VersaDoc imaging system (BioRad), using QuantityOne software (Hercules, CA, USA) for image capture and densitometry.

\section{Statistical analysis}

Data are reported as mean and standard error of the mean (SEM). Protein secretion and gene expression data in single time-point experiments were analyzed by oneway ANOVA followed by Tukey-Kramer's post-hoc test comparing all groups, or by Dunnett's post-hoc test comparing control to all others, as appropriate. Time course data were analyzed by two-way ANOVA followed by contrast testing. Student's t-test was used to examine syner- 
gistic effects of growth factors and cytokines. Real-time qPCR data were log-transformed prior to analysis.

\section{Results}

\section{Effect of PDGF-BB and TGF- $\beta$ on FLS secretion of} inflammatory mediators

Since PDGF and TGF- $\beta$ are abundant in the rheumatoid synovium, their effect on cytokine-induced inflammatory mediator secretion by FLS was examined. TGF- $\beta$ induced only a small amount of IL6 (Figure 1a), and no effect on IL6 (Figure 1a) or MMP3 (Figure 1b) was observed by PDGF-BB alone. PDGF and TGF- $\beta$ in combination (2GF) induced low-level secretion of IL6, but not MMPs or chemokines (Figures 1 and 2). The amount of IL6 secreted after 2GF stimulation was comparable to that observed with TNF $\alpha$ as the stimulant (Figure 2).

Surprisingly, the two growth factors in combination potently augmented secretion of IL6 (Figure 1a) and MMP3 (Figure 1b) in response to TNFa or IL1 $\beta$. The effect of $2 \mathrm{GF}$ was truly synergistic, in that the secretion observed by $2 \mathrm{GF}$ and TNF $\alpha$ or IL1 $\beta$ in combination was
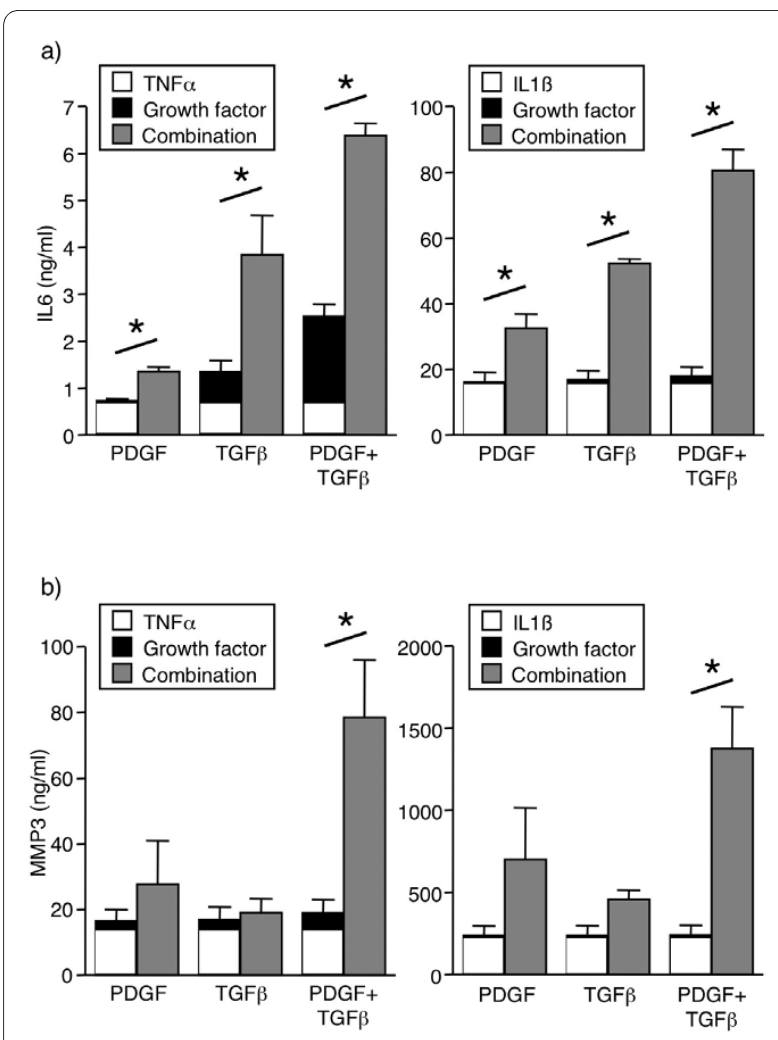

Figure 1 Potentiation by PDGF alone, TGF- $\beta$ alone, or their combination (2GF), of (a) IL6 and (b) MMP3 secretion from FLS. FLS were cultured for 24 hours with TNFa $(10 \mathrm{ng} / \mathrm{ml})$ or IL $1 \beta(2 \mathrm{ng} / \mathrm{ml})$, and/ or growth factors $(10 \mathrm{ng} / \mathrm{ml})$, and supernatants analyzed by ELISA. Mean \& SEM, $n=3$ RA FLS lines. Asterisk indicates $P<0.05$ between the combination and the added values for TNF alone and growth factor alone by Students' t-test.

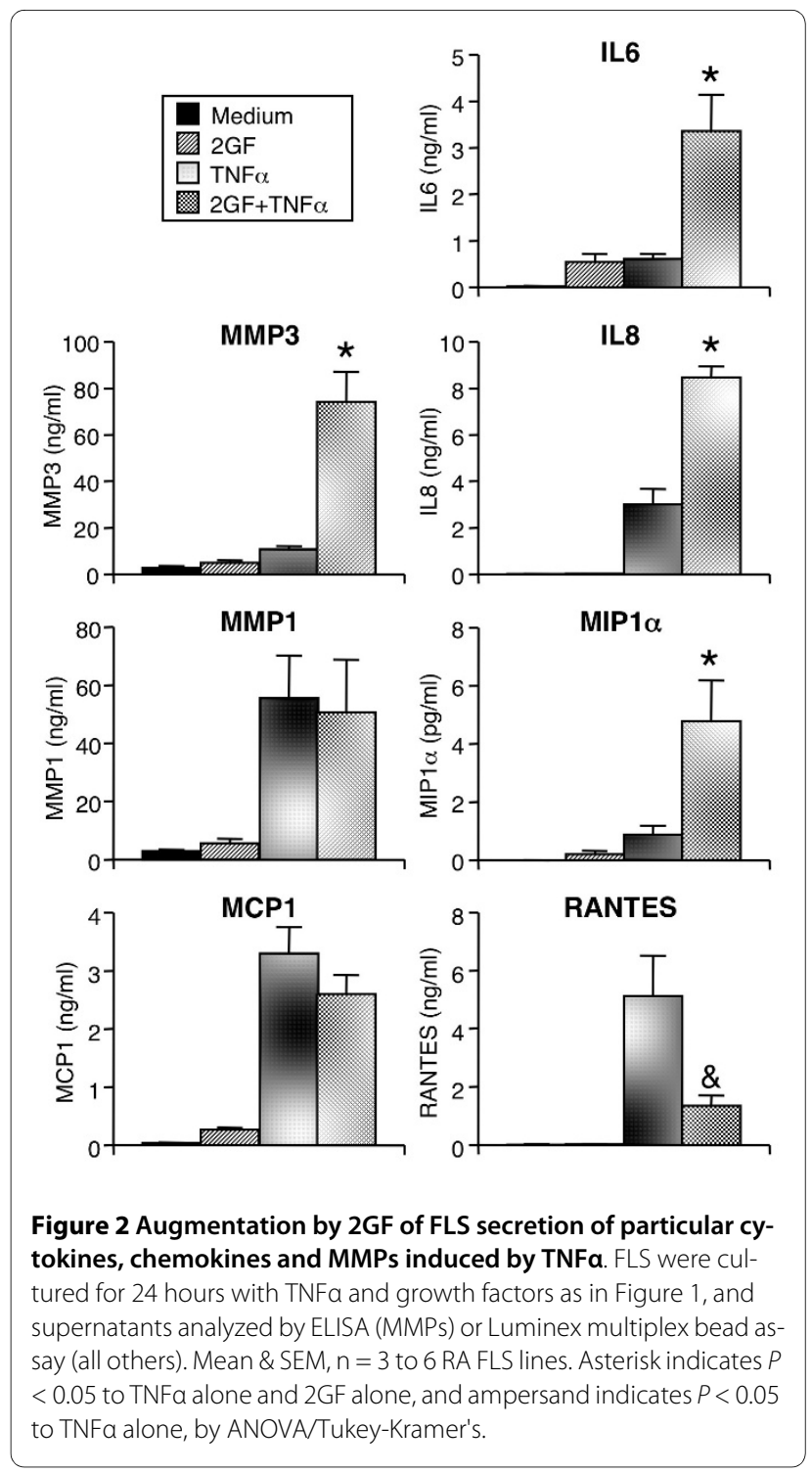

significantly higher than that obtained when adding the values for $2 \mathrm{GF}$ alone and cytokine alone (Figure 1). When PDGF-BB and TGF- $\beta$ were examined individually, neither augmented TNF- or IL1 $\beta$-induced MMP3 secretion, and the effect on TNF- or IL1 $\beta$-induced IL6 secretion was smaller than that of the growth factor combination (Figure 1). The potentiating effect of 2GF was not simply due to a non-specific effect of cell activation, since the secretion of some but not all mediators was affected. TNF $\alpha$-induced secretion of MMP1 and MCP1 was unaltered by addition of 2GF, and RANTES secretion was inhibited, at the same time that IL8 and MIP $1 \alpha$ secretion was potentiated (Figure 2) along with that of IL6 and MMP3.

The effect of 2GF was mediated through activation of growth factor receptors, since the receptor tyrosine kinase inhibitor, imatinib mesylate significantly reversed 
a)

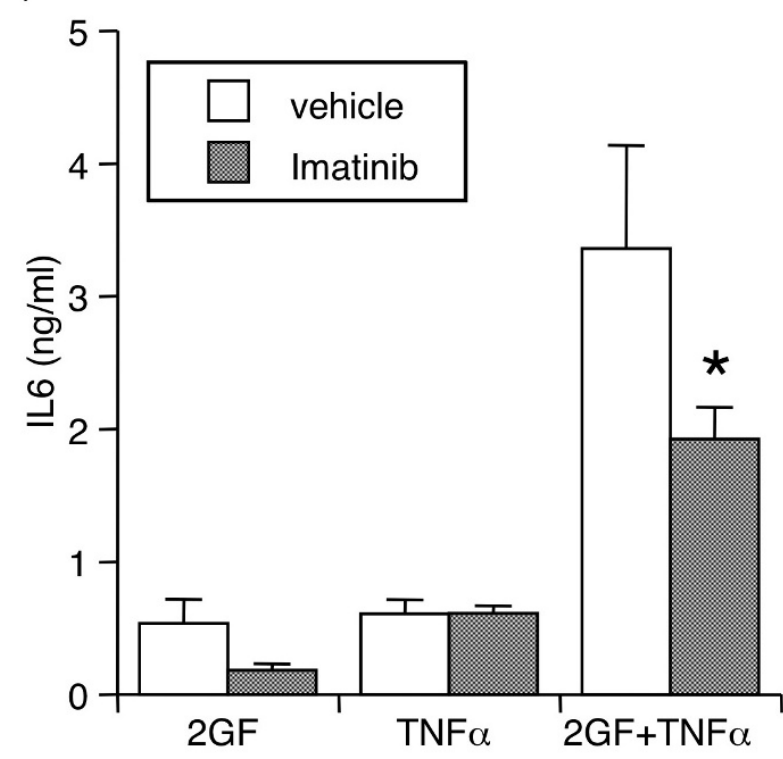

b)

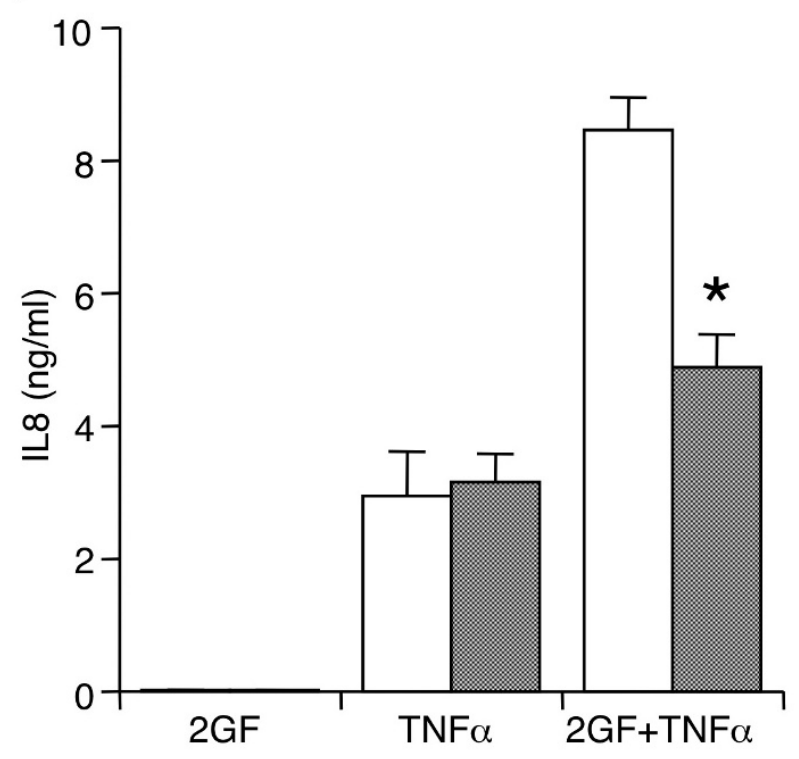

c)

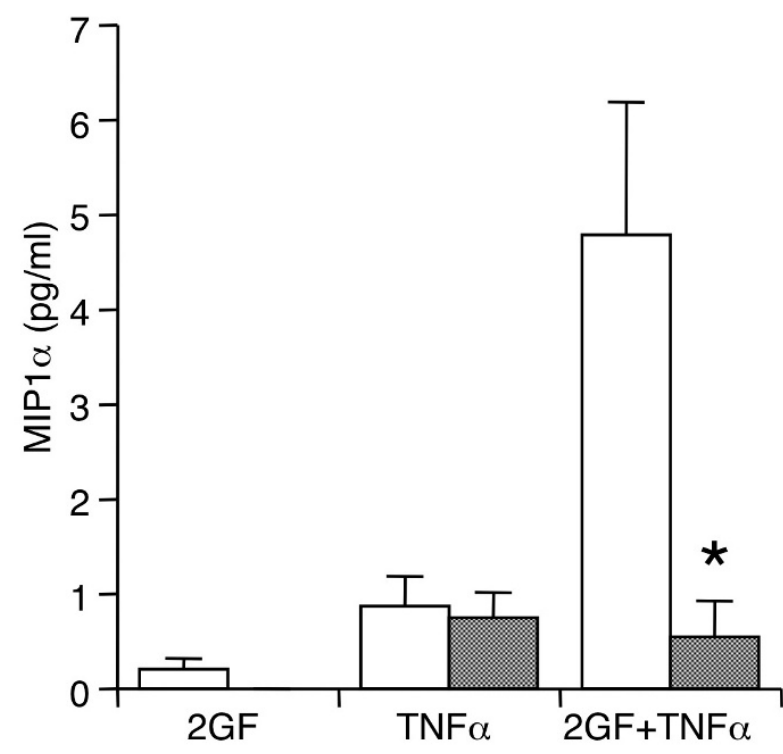

d)

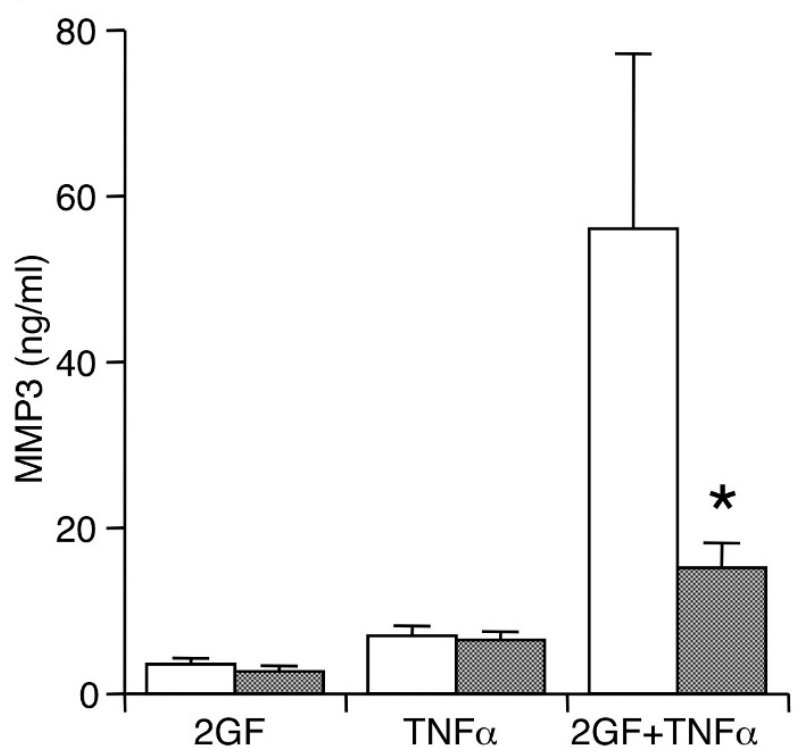

Figure 3 Reversal by imatinib ( $1 \mu \mathrm{M})$ of 2 GF potentiation of TNFa-induced (a) IL6, (b) IL8, (c) MIP1a, and (d) MMP3 secretion. For culture conditions and definitions, see legends for Figure 1 and 2. Supernatants were analyzed by ELISA or Luminex multiplex bead assay. Mean \& SEM, $n=3$ RA FLS lines. Asterisk indicates $P<0.05$ to vehicle by Students' t-test.

the potentiating effect of $2 \mathrm{GF}$ on TNF $\alpha$-induced secretion of IL6, IL8, MIP1 $\alpha$, and MMP3 (Figure 3). Importantly, imatinib did not alter secretion of these mediators in response to TNF $\alpha$ alone.

\section{Effect of PDGF-BB and TGF- $\beta$ on the time course of FLS mRNA expression}

In order to determine whether the effect of 2GF on FLS protein secretion was observed at the mRNA expression level, a time course experiment was conducted and the expression of IL6, MIP1 $\alpha$, and MMP3 mRNA in FLS was studied. TNF $\alpha$ caused a rapid rise in IL6 (Figure 4a) and MIP1 $\alpha$ (Figure 4b) mRNA expression, reaching a plateau at one hour and maintaining significant expression until the end of the experiment at $24 \mathrm{~h}$. 2GF alone induced a small amount of IL6 mRNA at three and eight hours, but no MIP $1 \alpha$. When 2 GF and TNF $\alpha$ was added in combina- 

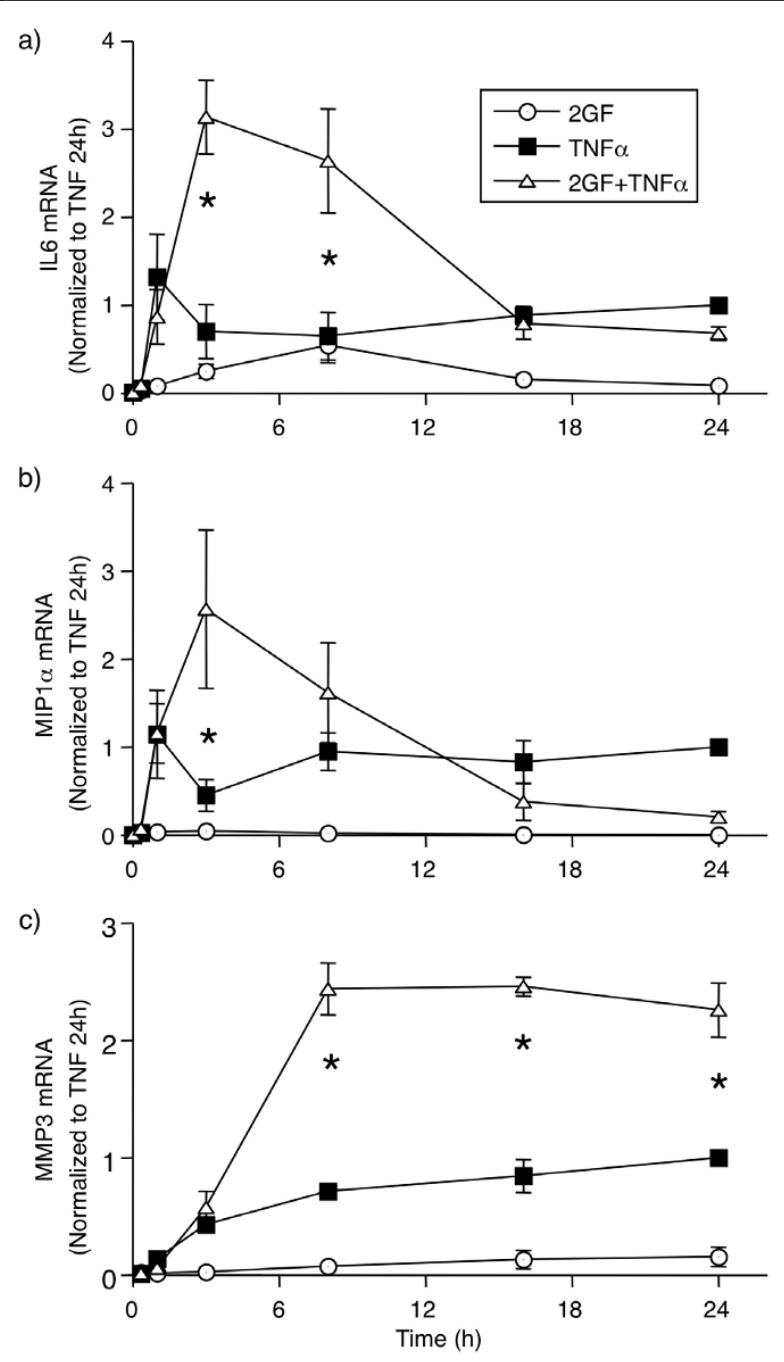

Figure 4 Time course of 2GF-induced potentiation of (a) IL6, (b) MIP1a and (c) MMP3 RNA induced by TNFa. FLS were cultured for indicated times with TNFa and growth factors, and mRNA levels quantified by real-time qPCR using GAPDH as housekeeper. Data are normalized to levels with TNFa alone at $24 \mathrm{~h}$. Mean \& SEM, $n=3$ RA FLS lines. Asterisk indicates $P<0.05$ to TNF alone and $2 \mathrm{GF}$ alone by twoway ANOVA and contrast testing on log-transformed data.

tion, significantly elevated IL6 levels were observed at three and eight hours (Figure 4a). For MIP1 $\alpha$ (Figure 4b), potentiation by $2 \mathrm{GF}$ of TNF $\alpha$-induced chemokine was only observed at three hours. Similar results were obtained for IL8 expression (data not shown). In the case of MMP3, TNF $\alpha$ alone induced a slow steady increase of mRNA levels evident from three hours and lasting until the end of the experiment at $24 \mathrm{~h}$. The addition of $2 \mathrm{GF}$ in combination with TNF $\alpha$ led to significantly elevated MMP3 levels at 8, 16 and $24 \mathrm{~h}$ (Figure 4c). Thus, the synergistic effect of $2 \mathrm{GF}$ on TNF $\alpha$-induced inflammatory mediator production by FLS is evident at the transcriptional level.

\section{Effect of temporal separation of the addition of growth factors and TNFa to FLS}

Next, the addition of $2 \mathrm{GF}$ and TNF $\alpha$ was separated in time to determine whether the potentiating effect of $2 \mathrm{GF}$ would be maintained. PDGF and TGF- $\beta$ were added at various time points in relation to $\mathrm{TNF} \alpha$, which was in turn allowed to stimulate the FLS for $24 \mathrm{~h}$ before supernatants were analyzed for secreted proteins. Under these conditions, 2GF was able to potentiate TNF $\alpha$-induced IL6, IL8 and MMP3 secretion when added at any time between $-2 \mathrm{~h}$ and $+2 \mathrm{~h}$ in relation to a TNF $\alpha$ addition (Figure 5a). The extent of the potentiating effect was similar to that observed when 2GF and TNF $\alpha$ were added simultaneously (crosshatched bars). For IL6 and MMP3 secretion, potentiation by $2 \mathrm{GF}$ was also observed when added as much as six hours prior to TNF $\alpha$ (Figure 5a).

In similar experiments studying the gene mRNA expression at three hours following TNF $\alpha$ addition, 2GF synergistically potentiated TNF $\alpha$-induced IL6 expression when added between $-4 \mathrm{~h}$ and $+2 \mathrm{~h}$ in relation to TNF $\alpha$ addition (Figure $5 \mathrm{~b}$ ). In separate experiments, FLS could be exposed to $2 \mathrm{GF}$ for as little as 15 minutes, even when added as early as four hours before TNF $\alpha$, and significantly elevated IL6 expression could still be noted (Figure $5 \mathrm{c})$. This suggests that the synergistic effect does not require continuous exposure to the $2 \mathrm{GF}$, and that it involves signaling pathways that are maintained over the course of several hours.

\section{Sustained activation of Erk and Akt in FLS by growth factors} For the purpose of elucidating the relevant signaling pathways causing the synergistic effect, FLS were treated with TNF $\alpha, 2 \mathrm{GF}$, or a combination for 15 minutes to four hours, and cell extracts analyzed by Western blot (Figure 6a). TNF $\alpha$ induced a short-lived peak of phosphorylation of p38, JNK isoforms, and ERK isoforms (Figure 6b-e) but had a marginal effect on Akt phosphorylation (Figure 6f). In contrast, 2GF induced a different pattern: phosphorylation of ERK and Akt that lasted for the four hours studied (Figure 6e-f), no phosphorylation of p38 (Figure 6b) nor JNK-p54 (Figure 6d), and a short-lived upregulation of phospho-JNK-p46 (Figure 6c). In combination, 2GF and TNF $\alpha$ generated phospho-protein levels similar to those induced by the mediators added separately, with the sole exception of phospho-JNK which was significantly higher after 15 minutes of $2 \mathrm{GF}+\mathrm{TNF} \alpha$ than after TNF alone or 2GF alone (Figure 6c, d). At the four-hour time point, no synergistic effect of $2 \mathrm{GF}$ and TNF $\alpha$ was noted on any phospho-protein studied. These studies 


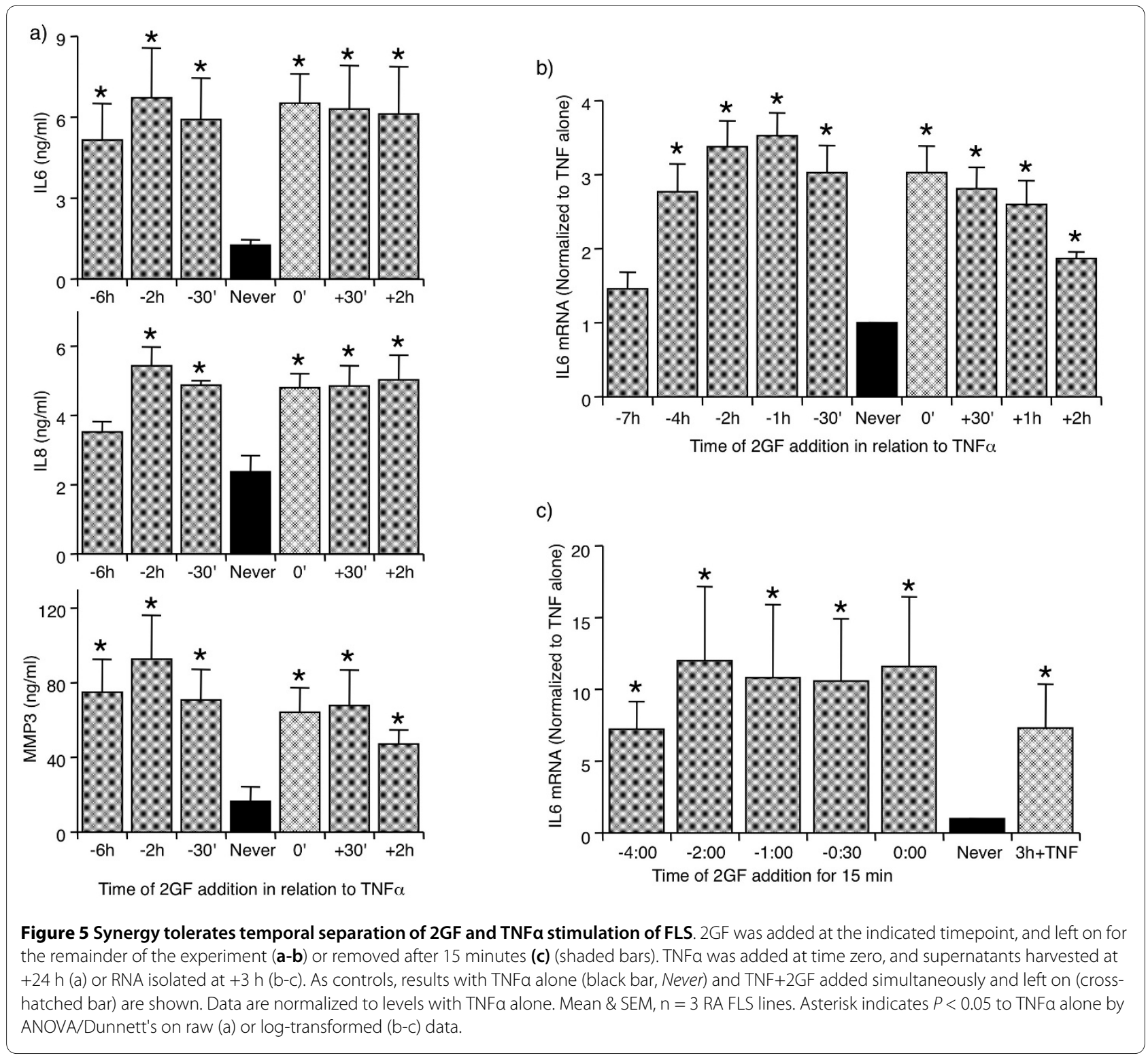

suggest focusing on the PI3K and MEK/ERK pathways as potentially responsible for the synergy.

\section{Effect of pharmacological inhibitors on 2GF potentiation of IL6 mRNA expression by FLS}

We tested the relative contributions of the ERK and PI3K signaling cascades to the synergistic effects of growth factors on gene expression using pharmacological inhibitors of ERK kinase (MEK1; PD98059) and PI3K (PI3K $\alpha$, PI3K $\beta$, PI3K $\gamma$ and PI3K $\delta ;$ LY294002). When 2GF and TNF $\alpha$ were added simultaneously in the presence of inhibitors, PD98059 had no effect on IL6 expression induced by any stimuli (Figure 7a). In contrast, the PI3K inhibitor, LY294002 had a significant effect on the IL6 expression induced by $2 \mathrm{GF}$ alone or TNF $\alpha$ alone, but in the case of the combination the effect, although evident, did not reach statistical significance (Figure 7a).

Since the interpretation of these results were complicated by the fact that LY294002 significantly inhibited the response to TNF $\alpha$ alone, $2 \mathrm{GF}$ were added to FLS cultures for 15 minutes only, and then soluble 2GF was removed by a medium change. Four hours later, TNF $\alpha$ was added and allowed to stimulate the FLS for a total of three hours, similar to the experiments shown in Figure 5c. The potentiating effect induced by $2 \mathrm{GF}$ under these conditions was significantly reversed if the PI3K inhibitor, LY294002, was included prior to the 2GF pulse (Figure 7b). In this study, LY294002 had no effect on the IL6 expression induced by TNF $\alpha$ alone in these experiments (Figure 7b), thus demonstrating that the effect was specific to 2GF-induced PI3K activity. Since the ERK path- 


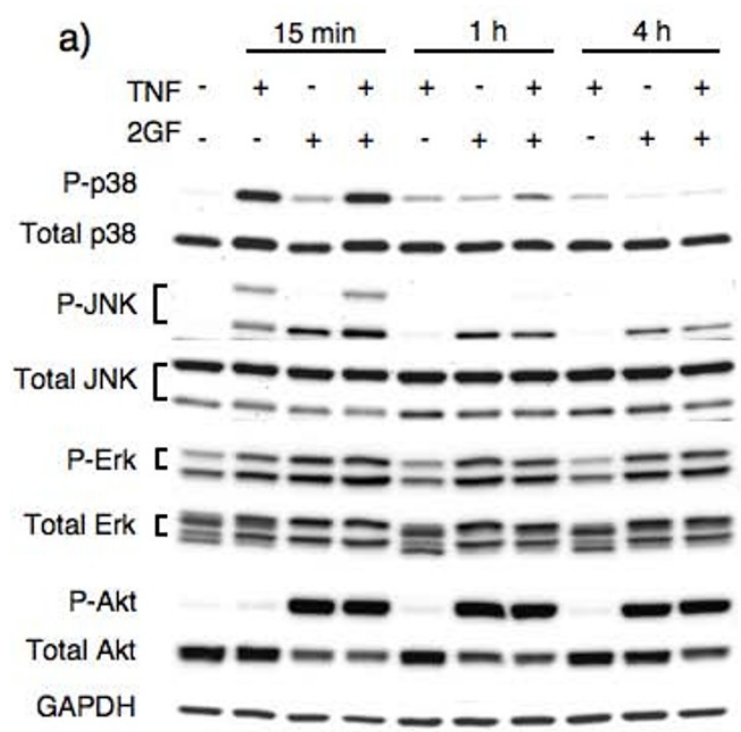

b)

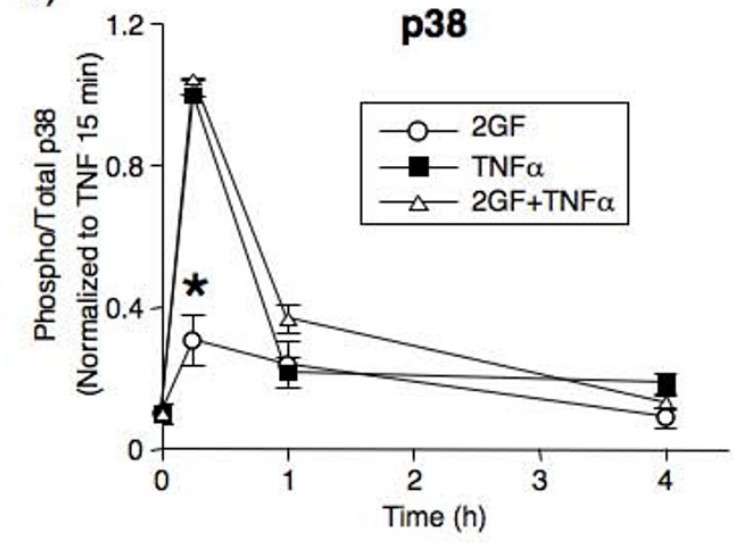

d)
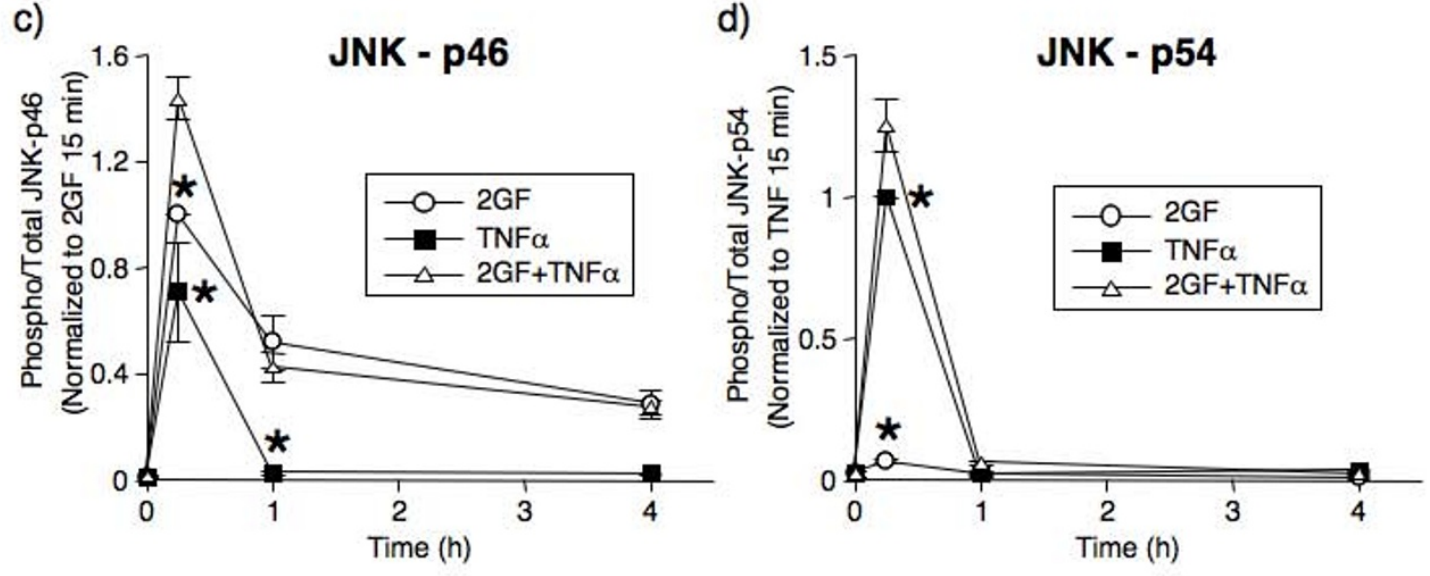

e)

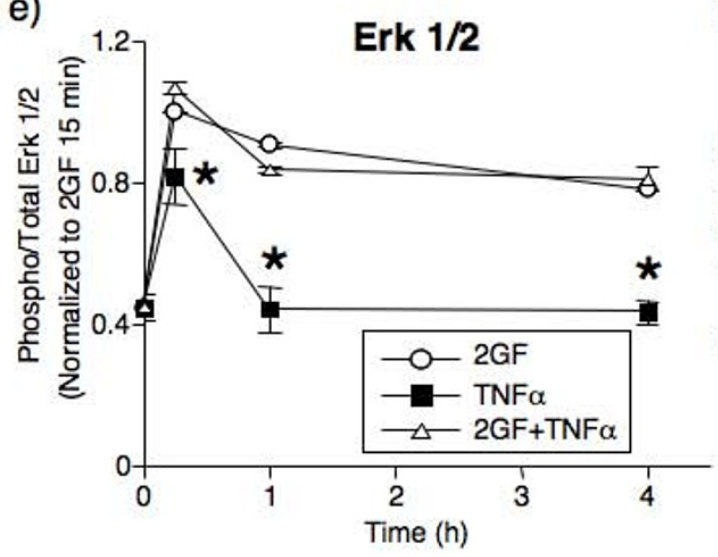

f)

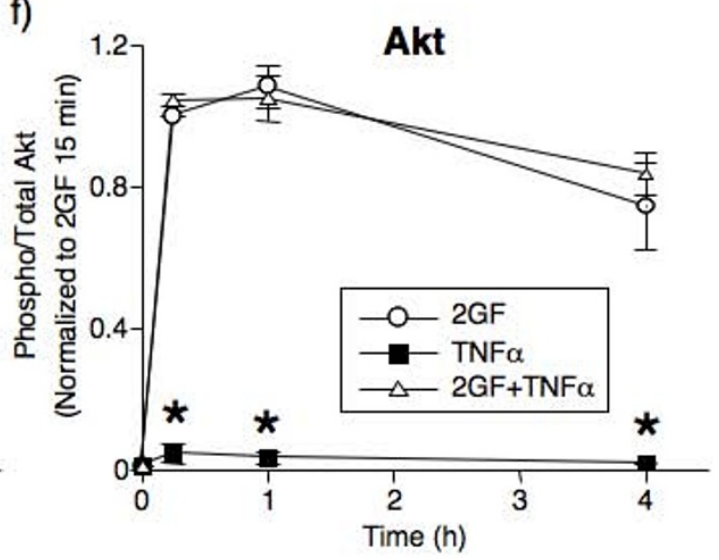

Figure 6 Time course of phospho-protein induction by TNFa, 2GF, or a combination in FLS. (a). Representative Western blot scans. GAPDH was used as loading control. (b)-(f). Ratios between phospho- and total MAPK and Akt as determined by densitometry. The two ERK isoforms were analyzed together (e). Data are normalized to 2 GF or TNFa alone at 15 minutes, as indicated. Mean \& SEM, $n=3$ RA FLS lines. Asterisk indicates $P<0.05$ to 2GF+TNFa by two-way ANOVA and contrast testing. 


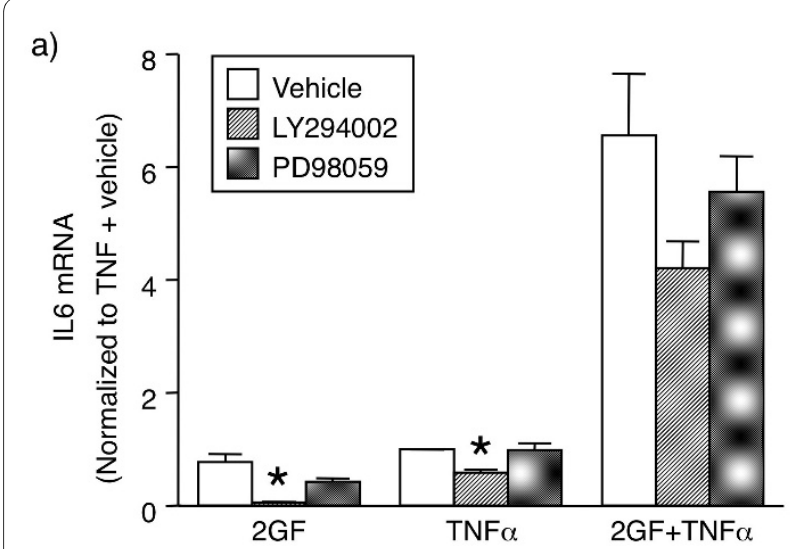

b)

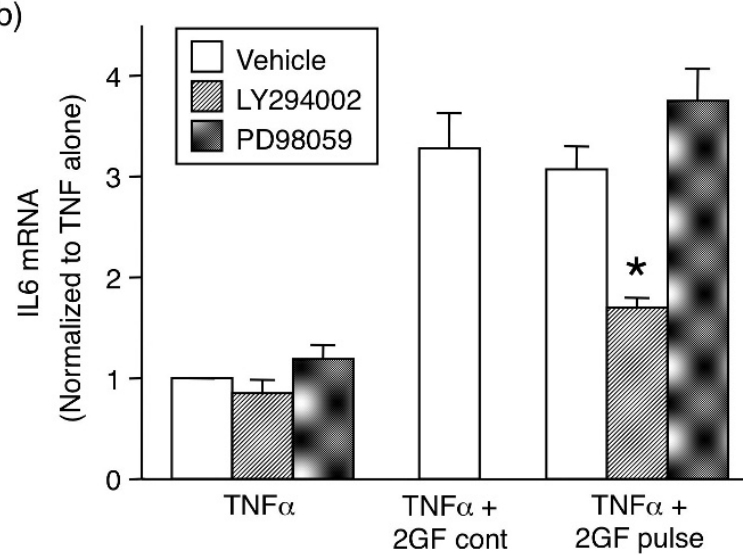

Figure 7 Involvement of $\mathrm{PI} 3$ kinase, but not Erk, in 2GF potentiation of TNFa-induced IL6 gene expression by FLS. (a). FLS were pre-

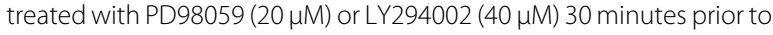
2GF and TNFa simultaneous addition. (b). Inhibitors were added at -4 h 30 minutes, $2 \mathrm{GF}-4 \mathrm{~h}$, and TNFa at time zero. 2GF were left on for the duration of the experiment (2GF cont) or left on for 15 minutes only (2GF pulse). RNA was isolated at three hours following TNFa stimulation. Data are normalized to levels with TNFa + vehicle. Asterisk indicates $P<0.05$ to respective vehicle by ANOVA/Dunnett's (a) or ANOVA/ Tukey-Kramer's (b) on log-transformed data.

way inhibitor had no effect in this system, these results indicate that activation of the PI3K pathway is a crucial step for the 2GF potentiation of TNF $\alpha$-induced gene expression in FLS.

\section{Discussion}

The chronically inflamed rheumatoid synovium is a complex environment with various cellular subtypes, cytokines, growth factors, chemokines, proteases and mechanical phenomena interacting with each other over time. Animal models may provide valuable insights into disease processes, but are limited in their ability to demonstrate specific target mediated effects that correspond to observations in RA. In addition, the typical rat and mouse models utilized, albeit useful in many ways, do not fully recapitulate human disease [16]. Studies of synovial tissue ex vivo can provide a snapshot of cellular activity in RA, and the accumulation of these observations provide insight into disease pathogenesis. In vitro studies of isolated human synovial cells can illuminate dynamic disease-specific cellular mechanisms. However, complete recapitulation of the RA synovial complexity in vitro is impractical if not impossible. Typical in vitro studies involve stimulating or activating cells, blocking signaling pathways and observing disease-relevant gene expression or proliferative outcomes. Interestingly, such studies have demonstrated what appear to be unresolved opposing effects of various mediators known to be present in the rheumatoid synovium. In this study we attempt to incrementally close the gap between cells and tissue by evaluating the role of peptide mediators historically identified as growth factors (PDGF and TGF- $\beta$ ) in providing a context for the response of FLS to inflammatory cytokines.

The surprising and novel central finding of these studies is the significant and striking synergistic effect of a combination of PDGF and TGF- $\beta$ on cytokine-induced FLS secretion of selected inflammatory mediators (IL6, IL8, MIP1 $\alpha$ and MMP3), while leaving some other mediators unaltered. Both PDGF and TGF- $\beta$ induce proliferation of FLS [3,5,7], and cytokine-induced growth of FLS is potentiated by PDGF [17] and TGF- $\beta$ [7]. Therefore, a potential reason for the synergistic effect of growth factors and cytokines on secretion of inflammatory mediators by FLS could simply be that a higher number of FLS are present after growth factor activation. This is unlikely to provide an explanation for our findings, however, for two reasons. First, FLS are slow growing cells [14] and the relatively short incubation times employed in the current studies ( $3 \mathrm{~h}$ for mRNA, $24 \mathrm{~h}$ for protein secretion) make it unlikely that a significantly higher number of FLS could have been generated. Second, in the mRNA expression studies, all data were normalized to GAPDH for the purpose of controlling for cell numbers. Since the mRNA and protein results essentially mirrored each other (compare for example Figures 2 and 4, and Figures $5 \mathrm{a}$ and $5 \mathrm{~b}$ ), the underlying reason for the synergy of the two growth factors along with cytokines on FLS is unlikely to be simply an effect on cell number.

To our knowledge, this report is the first to establish a synergy of the combined effects of PDGF and TGF- $\beta$ on cytokine-induced gene expression in FLS. The underlying signaling mechanisms are not entirely clear. However, the effect is receptor-mediated as demonstrated by the reversing action of imatinib mesylate, also known as Gleevec. This compound is a moderately selective tyrosine kinase inhibitor that targets several classes of receptor kinases including abl [18], c-kit [19], c-fms (the M-CSF receptor) [20], and PDGF receptor kinases $[18,21]$. In FLS, imatinib blocks PDGF-induced prolifera- 
tion and phosphorylation of downstream targets of PDGF receptor stimulation [22-25]. Due to its inhibition of abl, imatinib also has a role in TGF- $\beta$ induced signaling and fibrogenesis in cultured fibroblasts [26,27]. Hence, the reversal of the growth factor-induced synergy by imatinib indicates involvement of specific growth factor signaling pathways.

With respect to common signaling pathways in fibroblasts, both PDGF and TGF- $\beta$ are known to activate the PI3K [28,29] and the Ras-Raf-MEK-ERK pathways $[30,31]$. Indeed, both Akt and ERK were phosphorylated for at least four hours by 2GF treatment of FLS, making them attractive signaling candidates. The testing of this hypothesis was complicated by the fact that the PI3K inhibitor used (LY294002) had significant effects on IL6 expression induced by TNF $\alpha$ alone, as earlier reported [32] and similar to earlier published results where IL17 was used to induce IL6 [33]. To circumvent this problem, we took advantage of the fact that a short pulse of $2 \mathrm{GF}$, separated in time from the TNF $\alpha$ stimulation, was capable of potentiating TNF $\alpha$-induced IL6 expression to the same extent as continuous incubation with $2 \mathrm{GF}$ without affecting signaling in FLS stimulated with TNF $\alpha$ alone. In this system, LY294002 added before 2GF and removed prior to the addition of TNF $\alpha$ significantly blocked the synergy, demonstrating a PI3K role. The ERK pathway, however, did not appear to play a role, at least at levels distal to MEK1. Thus, PI3K constitutes a pharmacological target of interest for synovitis mediated by this mechanism. Indeed, studies antagonizing PI3K signaling have shown promise in animal models of arthritis. Gene transfer of a negative regulator of PI3K signalling, PTEN, ameliorates collagen arthritis [34] and in murine models of arthritis, inhibitors of the gamma isoform PI3K have been shown to reduce joint destruction [35]. Notably, this particular isoform was recently demonstrated to be specifically upregulated in human RA FLS [36].

These findings, in addition to demonstrating novel synergistic effects of growth factors and cytokines on FLS, may also have clinical implications. In particular, the effect of imatinib is of interest, since this compound is already in clinical use for Philadelphia chromosome-positive hematological malignancies [37] as well as for gastrointestinal stromal tumor [38]. A few case reports exist $[39,40]$ of imatinib mesylate as a successful treatment for refractory RA, with reductions in swollen joint counts and CRP observed. In addition, a phase II study of imatinib in RA has been completed (Clinicaltrials.gov identifier \# NCT00154336), however the results have not yet been made publicly available. In animal models, imatinib limits joint inflammation in mouse collagen arthritis $[23,41]$ and rat adjuvant arthritis [25], and reduces joint destruction in collagen arthritis in rats [42]. Additionally, in preliminary studies in our laboratory, imatinib limited the arthritis induced by $\mathrm{K} / \mathrm{BxN}$ serum transfer (data not shown), a murine model in which the adaptive immune system has been bypassed. The precise mechanism of imatinib in RA is not known and could involve downregulation of the function of a number of cell types, as shown in vitro: $\mathrm{T}$ and $\mathrm{B}$ lymphocytes [23,43], macrophages $[20,44]$, osteoclasts [42], and mast cells [23,45]. The studies described herein provide yet another potential explanation for the effect of imatinib in arthritis: inhibition of a two-legged response by FLS, which require both a cytokine and growth factors to become activated to its fullest potential.

\section{Conclusions}

PDGF and TGF- $\beta$ strongly and selectively potentiate cytokine-induced synthesis and secretion of certain proinflammatory factors by FLS, such as IL6, IL8, MIP1 $\alpha$, and MMP3. The synergy was transcriptionally regulated, and endured for at least several hours after withdrawal of the growth factors. These data are consistent with a model wherein PDGF and TGF- $\beta$ direct the response of synovial cells toward an RA phenotype and may partially explain the aggressiveness of RA synovitis. Both imatinib mesylate and a PI3K inhibitor were found to reverse this synergy. Therefore, targeting growth factor signaling may provide an additional approach to breaking the cycle of sustained synovitis in RA with the goal of restoring synovial homeostasis.

\section{Abbreviations}

2GF: both TGF- $\beta$ and PDGF were used together; Ct: threshold cycle; FLS: fibroblast-like synoviocytes; L: interleukin; MIP1a: macrophage inflammatory protein 1 alpha; MMP: matrix metalloproteinase; PDGF: platelet-derived growth factor; RA: rheumatoid arthritis; REU: relative expression units; TGF- $\beta$ : transforming growth factor beta; TNFa: tumor necrosis factor-alpha.

\section{Competing interests}

The authors declare that they have no competing interests.

\section{Authors' contributions}

SR designed and performed the experiments and statistical analysis, and prepared the manuscript. MPC provided the animal model and edited the manuscript; and DLB conceived of the study, designed experiments, and edited the manuscript.

\section{Acknowledgements}

This work was supported, in part, by the UCSD Clinical and Translational Research Institute.

\section{Author Details}

Division of Rheumatology, Allergy and Immunology, University of California at San Diego School of Medicine, 9500 Gilman Drive, La Jolla, CA 92093-0656, USA

Received: 30 September 2009 Revised: 19 February 2010

Accepted: 9 April 2010 Published: 9 April 2010

\section{References}

1. Lafyatis R, Thompson NL, Remmers EF, Flanders KC, Roche NS, Kim SJ, Case JP, Sporn MB, Roberts AB, Wilder RL: Transforming growth factorbeta production by synovial tissues from rheumatoid patients and streptococcal cell wall arthritic rats. Studies on secretion by synovial 
fibroblast-like cells and immunohistologic localization. J Immunol 1989, 143:1142-1148.

2. Remmers EF, Sano H, Lafyatis R, Case JP, Kumkumian GK, Hla T, Maciag T, Wilder RL: Production of platelet derived growth factor B chain (PDGF$\mathrm{B} / \mathrm{c}$-sis) mrna and immunoreactive PDGF B-like polypeptide by rheumatoid synovium: coexpression with heparin binding acidic fibroblast growth factor-1. J Rheumatol 1991, 18:7-13.

3. Thornton SC, Por SB, Penny R, Richter M, Shelley L, Breit SN: Identification of the major fibroblast growth factors released spontaneously in inflammatory arthritis as platelet derived growth factor and tumour necrosis factor-alpha. Clin Exp Immunol 1991, 86:79-86.

4. Chu CQ, Field M, Abney E, Zheng RQ, Allard S, Feldmann M, Maini RN: Transforming growth factor-beta 1 in rheumatoid synovial membrane and cartilage/pannus junction. Clin Exp Immunol 1991, 86:380-386.

5. Remmers EF, Sano H, Wilder RL: Platelet-derived growth factors and heparin-binding (fibroblast) growth factors in the synovial tissue pathology of rheumatoid arthritis. Semin Arthritis Rheum 1991 21:191-199.

6. Li MO, Wan YY, Sanjabi S, Robertson AK, Flavell RA: Transforming growth factor-beta regulation of immune responses. Annu Rev Immunol 2006, 24:99-146.

7. Wahl SM, Allen JB, Wong HL, Dougherty SF, Ellingsworth LR: Antagonistic and agonistic effects of transforming growth factor-beta and IL-1 in rheumatoid synovium. J Immunol 1990, 145:2514-2519.

8. Yamanishi Y, Boyle DL, Clark M, Maki RA, Tortorella MD, Arner EC, Firestein GS: Expression and regulation of aggrecanase in arthritis: the role of TGF-beta. J Immunol 2002, 168:1405-1412.

9. Thorbecke GJ, Shah R, Leu CH, Kuruvilla AP, Hardison AM, Palladino MA: Involvement of endogenous tumor necrosis factor alpha and transforming growth factor beta during induction of collagen type II arthritis in mice. Proc Natl Acad Sci USA 1992, 89:7375-7379.

10. Allen JB, Manthey CL, Hand AR, Ohura K, Ellingsworth L, Wahl SM: Rapid onset synovial inflammation and hyperplasia induced by transforming growth factor beta. J Exp Med 1990, 171:231-247.

11. Kumkumian GK, Lafyatis R, Remmers EF, Case JP, Kim SJ, Wilder RL: Platelet-derived growth factor and IL-1 interactions in rheumatoid arthritis. Regulation of synoviocyte proliferation, prostaglandin production, and collagenase transcription. J Immunol 1989, 143:833-837.

12. Cheon H, Sun YK, Yu SJ, Lee YH, Ji JD, Song GG, Lee JH, Kim MK, Sohn J: Platelet-derived growth factor-AA increases IL-1 beta and IL-8 expression and activates NF-kappab in rheumatoid fibroblast-like synoviocytes. Scand I Immunol 2004, 60:455-462.

13. Cho ML, Min SY, Chang SH, Kim KW, Heo SB, Lee SH, Park SH, Cho CS, Kim HY: Transforming growth factor beta 1(TGF-beta1) down-regulates tnfalpha-induced RANTES production in rheumatoid synovial fibroblasts through NF-kappab-mediated transcriptional repression. Immunol Lett 2006, 105:159-166.

14. Rosengren S, Boyle DL, Firestein GS: Acquisition, culture, and phenotyping of synovial fibroblasts. Methods Mol Med 2007, 135:365-375.

15. Boyle DL, Rosengren S, Bugbee W, Kavanaugh A, Firestein GS: Quantitative biomarker analysis of synovial gene expression by realtime PCR. Arthritis Res Ther 2003, 5:R352-360

16. Hegen M, Keith JC Jr, Collins M, Nickerson-Nutter CL: Utility of animal models for identification of potential therapeutics for rheumatoid arthritis. Ann Rheum Dis 2008, 67:1505-1515.

17. Hamilton JA, Butler DM, Stanton H: Cytokine interactions promoting DNA synthesis in human synovial fibroblasts. J Rheumatol 1994, 21:797-803

18. Druker BJ, Tamura S, Buchdunger E, Ohno S, Segal GM, Fanning S, Zimmermann J, Lydon NB: Effects of a selective inhibitor of the Abl tyrosine kinase on the growth of Bcr-Abl positive cells. Nat Med 1996, 2:561-566.

19. Buchdunger E, Cioffi CL, Law N, Stover D, Ohno-Jones S, Druker BJ, Lydon NB: Abl protein-tyrosine kinase inhibitor STI571 inhibits in vitro signal transduction mediated by c-kit and platelet-derived growth factor receptors. J Pharmacol Exp Ther 2000, 295:139-145.

20. Dewar AL, Cambareri AC, Zannettino AC, Miller BL, Doherty KV, Hughes TP, Lyons AB: Macrophage colony-stimulating factor receptor c-fms is a novel target of imatinib. Blood 2005, 105:3127-3132.
21. Carroll M, Ohno-Jones S, Tamura S, Buchdunger E, Zimmermann J, Lydon NB, Gilliland DG, Druker BJ: CGP 57148, a tyrosine kinase inhibitor, inhibits the growth of cells expressing BCR-ABL, TEL-ABL, and TELPDGFR fusion proteins. Blood 1997, 90:4947-4952.

22. Kameda $H$, Ishigami $H$, Suzuki $M$, Abe $T$, Takeuchi T: Imatinib mesylate inhibits proliferation of rheumatoid synovial fibroblast-like cells and phosphorylation of Gab adapter proteins activated by platelet-derived growth factor. Clin Exp Immunol 2006, 144:335-341.

23. Paniagua RT, Sharpe O, Ho PP, Chan SM, Chang A, Higgins JP, Tomooka BH, Thomas FM, Song JJ, Goodman SB, Lee DM, Genovese MC, Utz PJ, Steinman L, Robinson WH: Selective tyrosine kinase inhibition by imatinib mesylate for the treatment of autoimmune arthritis. $J$ Clin Invest 2006, 116:2633-2642.

24. Sandler C, Joutsiniemi S, Lindstedt KA, Juutilainen T, Kovanen PT, Eklund KK: Imatinib mesylate inhibits platelet derived growth factor stimulated proliferation of rheumatoid synovial fibroblasts. Biochem Biophys Res Commun 2006, 347:31-35.

25. Terabe F, Kitano M, Kawai M, Kuwahara Y, Hirano T, Arimitsu J, Hagihara K, Shima Y, Narazaki M, Tanaka T, Kawase I, Sano H, Ogata A: Imatinib mesylate inhibited rat adjuvant arthritis and PDGF-dependent growth of synovial fibroblast via interference with the Akt signaling pathway. Mod Rheumatol 2009, 19:522-529.

26. Daniels CE, Wilkes MC, Edens M, Kottom TJ, Murphy SJ, Limper AH, Leof EB: Imatinib mesylate inhibits the profibrogenic activity of TGF-beta and prevents bleomycin-mediated lung fibrosis. J Clin Invest 2004, 114:1308-1316.

27. Wang $S$, Wilkes $M C$, Leof EB, Hirschberg R: Imatinib mesylate blocks a non-Smad TGF-beta pathway and reduces renal fibrogenesis in vivo. Faseb J 2005, 19:1-11.

28. Kavanaugh WM, Klippel A, Escobedo JA, Williams LT: Modification of the 85-kilodalton subunit of phosphatidylinositol-3 kinase in plateletderived growth factor-stimulated cells. Mol Cell Biol 1992, 12:3415-3424.

29. Kim G, Jun JB, Elkon KB: Necessary role of phosphatidylinositol 3-kinase in transforming growth factor beta-mediated activation of Akt in normal and rheumatoid arthritis synovial fibroblasts. Arthritis Rheum 2002, 46:1504-1511.

30. Mucsi I, Skorecki KL, Goldberg HJ: Extracellular signal-regulated kinase and the small GTP-binding protein, Rac, contribute to the effects of transforming growth factor-beta1 on gene expression. J Biol Chem 1996, 271:16567-16572.

31. Heldin CH, Ostman A, Ronnstrand L: Signal transduction via plateletderived growth factor receptors. Biochim Biophys Acta 1998, 1378:F79-113

32. $X u H$, He Y, Yang $X$, Liang L, Zhan Z, Ye Y, Yang X, Lian F, Sun L: Antimalarial agent artesunate inhibits TNF-alpha-induced production of proinflammatory cytokines via inhibition of NF-kappab and PI3 kinase/ Akt signal pathway in human rheumatoid arthritis fibroblast-like synoviocytes. Rheumatology (Oxford) 2007, 46:920-926

33. Hwang SY, Kim JY, Kim KW, Park MK, Moon Y, Kim WU, Kim HY: IL-17 induces production of IL- 6 and IL- 8 in rheumatoid arthritis synovial fibroblasts via NF-kappab- and PI3-kinase/Akt-dependent pathways. Arthritis Res Ther 2004, 6:R120-128.

34. Wang CR, Shiau AL, Chen SY, Lin LL, Tai MH, Shieh GS, Lin PR, Yo YT, Lee $\mathrm{CH}$, Kuo SM, Liu MF, Jou IM, Yang CY, Shen PC, Lee HL, Wu CL: Amelioration of collagen-induced arthritis in rats by adenovirusmediated PTEN gene transfer. Arthritis Rheum 2008, 58:1650-1656.

35. Marone R, Cmiljanovic V, Giese B, Wymann MP: Targeting phosphoinositide 3-kinase: moving towards therapy. Biochim Biophys Acta 2008, 1784:159-185.

36. Hayer S, Pundt N, Peters MA, Wunrau C, Kuhnel I, Neugebauer K, Strietholt S, Zwerina J, Korb A, Penninger J, Joosten LA, Gay S, Ruckle T, Schett G, Pap $\mathrm{T}$ : PI3Kgamma regulates cartilage damage in chronic inflammatory arthritis. Faseb J 2009, 23:4288-4298.

37. Yanada M, Naoe T: Imatinib combined chemotherapy for Philadelphia chromosome-positive acute lymphoblastic leukemia: major challenges in current practice. Leuk Lymphoma 2006, 47:1747-1753.

38. Quek R, George S: Gastrointestinal stromal tumor: a clinical overview. Hematol Oncol Clin North Am 2009, 23:69-78. viii

39. Eklund KK, Joensuu $H$ : Treatment of rheumatoid arthritis with imatinib mesylate: clinical improvement in three refractory cases. Ann Med 2003, 35:362-367. 
40. Miyachi K, Ihara A, Hankins RW, Murai R, Maehiro S, Miyashita H: Efficacy of imatinib mesylate (STI571) treatment for a patient with rheumatoid arthritis developing chronic myelogenous leukemia. Clin Rheumatol 2003, 22:329-332.

41. Koyama K, Hatsushika K, Ando T, Sakuma M, Wako M, Kato R, Haro H, Sugiyama H, Hamada Y, Ogawa H, Nakao A: Imatinib mesylate both prevents and treats the arthritis induced by type II collagen antibody in mice. Mod Rheumatol 2007, 17:306-310.

42. Ando W, Hashimoto J, Nampei A, Tsuboi H, Tateishi K, Ono T, Nakamura N, Ochi T, Yoshikawa H: Imatinib mesylate inhibits osteoclastogenesis and joint destruction in rats with collagen-induced arthritis (CIA). J Bone Miner Metab 2006, 24:274-282.

43. Leder C, Ortler S, Seggewiss R, Einsele H, Wiendl H: Modulation of Teffector function by imatinib at the level of cytokine secretion. Exp Hematol 2007, 35:1266-1271.

44. Taylor JR, Brownlow N, Domin J, Dibb NJ: FMS receptor for M-CSF (CSF-1) is sensitive to the kinase inhibitor imatinib and mutation of Asp-802 to Val confers resistance. Oncogene 2006, 25:147-151.

45. Juurikivi A, Sandler C, Lindstedt KA, Kovanen PT, Juutilainen T, Leskinen MJ, Maki T, Eklund KK: Inhibition of c-kit tyrosine kinase by imatinib mesylate induces apoptosis in mast cells in rheumatoid synovia: a potential approach to the treatment of arthritis. Ann Rheum Dis 2005, 64:1126-1131.

doi: 10.1186/ar2981

Cite this article as: Rosengren et al., Platelet-derived growth factor and transforming growth factor beta synergistically potentiate inflammatory mediator synthesis by fibroblast-like synoviocytes Arthritis Research \& Therapy 2010, 12:R65

Submit your next manuscript to BioMed Central and take full advantage of:

- Convenient online submission

- Thorough peer review

- No space constraints or color figure charges

- Immediate publication on acceptance

- Inclusion in PubMed, CAS, Scopus and Google Scholar

- Research which is freely available for redistribution

Submit your manuscript at www.biomedcentral.com/submit
C Biomed Central 